\title{
POLÍTICAS DE CIÊNCIA, TECNOLOGIA E INOVAÇÃO (CT\&I) EM UM SISTEMA DE INOVAÇÃO IMATURO: O PROGRAMA DE APOIO À PESQUISA EM EMPRESAS (PAPPE) NA REGIÃO CENTRO-OESTE
}

\author{
Carla Cristina Rosa de Almeida - UFMT \\ Priscila Gomes de Castro - IFMT \\ Vinícius Salatin Corrêa - UFSCAR \\ Suzana da Silva Soares - UNEMAT \\ Tatiane da Cunha Villela - UNEMAT
}

\section{Resumo}

A concentração territorial das bases científicas e tecnológicas tem sido apontada como um dos fatores que impedem a redução das desigualdades regionais. No contexto nacional, a região Centro-Oeste tem, comparativamente, uma frágil infraestrutura científico-tecnológica, muito embora os estados da região venham direcionando políticas públicas para minimização da deficiência nas áreas de ciência, tecnologia e inovação (CT\&I), como o Programa de Apoio à Pesquisa em Empresas (Pappe). Assim, este artigo analisa os resultados do Pappe na região Centro-Oeste, segundo a visão das empresas beneficiadas com recursos de subvenção direcionados à inovação entre 2004 e 2011. Observou-se que o programa produziu resultados positivos em termos de geração de mercados e postos de trabalho, contudo, quanto à mudança tecnológica, as firmas realizaram inovações, mas não foram capazes de alocar produto novo para o mercado e geraram baixo número de patentes. Também, não aumentaram as relações de cooperação entre os agentes envolvidos. Os resultados apontam para a necessidade de ampliação e aprimoramento das políticas de C,T\&I na região, definindo prioridades e traçando metas, de forma a gerar mecanismos facilitadores da interação entre os agentes do sistema de inovação que favoreçam o desenvolvimento regional.

Palavras chaves: Sistemas de inovação; subvenção econômica, mudança tecnológica, micro e pequenas empresas.

\begin{abstract}
The territorial concentration of scientific and technological bases has been considered one of the factors that prevent the reduction of regional inequalities. In the national context, the Brazilian Central West region has comparatively brittle scientific and technological infrastructure, although the states of the region have been directing public policies to reduce defiency in the areas of science, technology and innovation (ST\&I) as the "Programa de Apoio à Pesquisa em Empresas" (Pappe). Thus, this article analyzes the Pappe's results in the Central West region, according to the companies' vision from grant funds allocated to innovation, between the years of 2004 and 2011. It was observed that the program produced positive results in terms of generating markets and jobs, but, concerning technological change, firms conducted innovations, but they were not able to allocate new product to the market and they generated few patents. Also, they did not increase their cooperation relations between the agents involved. The results indicate the need to expand and improving ST\&I policies in the region, by defining priorities and goals, in order to create mechanisms that facilitate interaction between the innovation system agents and promote regional development.
\end{abstract}

Key words: Innovation systems; economic grants, technological change, micro and small companies.

Indicação da Área ABEIN: Área 8 - Políticas de Ciência, Tecnologia e Inovação

Classificação JEL: O3 Innovation • Research and Development • Technological Change • Intellectual Property Rights / O38 Government Policy 


\section{Introdução}

Dentre as políticas de estímulo à ciência, tecnologia e inovação (CT\&I), os incentivos fiscais às empresas justificam-se diante da discrepância entre altos retornos sociais e os baixos retornos privados dos investimentos na produção de conhecimento (ROSENBERG, 2006). Em comparação aos países desenvolvidos, tais mecanismos de financiamento foram incorporados tardiamente no Brasil, somente nos aos 2000, sobretudo por meio da redução fiscal e subvenção econômica - estimulados a partir da Lei da Inovação ${ }^{1}$ e Lei do Bem² (MORAIS, 2007).

Consequentemente, o papel das políticas de CT\&I também foram, por muito tempo, negligenciados nas discussões sobre desenvolvimento regional, ao mesmo tempo em que as proposições de políticas focaram-se nos benefícios fiscais e financeiros para atração de investimentos (CAVALCANTE, 2011, FONSECA, 2012). Diante da concentração regional das bases científicas e tecnológicas, trabalhos recentes têm enfatizado a relevância do papel da inovação para redução das desigualdades, salientando que "políticas de desenvolvimento regional apoiadas apenas na combinação de incentivos fiscais e financeiros têm limitadas possibilidades de sustentação no longo prazo" (CAVALCANTE, 2011, p. 9).

O alto grau de imaturidade do Sistema Nacional de Inovação (SNI) brasileiro, com conexões apenas parciais entre a dimensão científica e tecnológica (SUZIGAN; ALBUQUERQUE, 2011), agravase diante do desequilíbrio entre as diferentes regiões. Assim, “os estados mais desenvolvidos e com maior capacidade de CT\&I instalada são os que atraem a maior parte dos investimentos públicos; e são, também, aqueles que possuem as melhores condições de fazer investimentos com recursos orçamentários próprios” (FONSECA, 2012, p. 7). A concentração da base científica, sobretudo de doutores e de cursos de pós-graduação, também retroalimenta a centralização dos recursos federais para as instituições de ensino superior e pesquisas do Sudeste e Sul do país (CAVALCANTE, 2011; FONSECA, 2012).

Nesse contexto, os indicadores da região Centro-Oeste demonstram frágil infraestrutura científicotecnológica, com fracas relações entre universidades e empresas. Embora as políticas de CT\&I de cunho federal reflitam fracos desdobramentos para as políticas públicas regionais, observou-se, na última década, um maior direcionamento de políticas públicas estaduais para as áreas de CT\&I, além da maior absorção de recursos humanos mais qualificados para realização de atividades acadêmicas. Concomitantemente, após meados de 2000, observa-se maior interesse dos governos estaduais em fortalecer suas Fundações de Amparo à Pesquisa (FAP), assim como promover aprimoramentos institucionais que fomentem a iniciativa privada no desenvolvimento e aplicação de maior conteúdo tecnológico e inovações (ALMEIDA et. al., 2011; ALMEIDA, POVOA, 2011).

Dentre as iniciativas direcionadas as micro e pequenas empresas (MPEs), destaca-se o Programa de Apoio à Pesquisa em Empresas (Pappe), decorrente de uma parceria entre a Financiadora de Estudos e Projetos (FINEP) e as FAPs, com “(...) objetivo de apoiar financeiramente, através de subvenção, projetos inovadores que fossem desenvolvidos em conjunto por empresas e pesquisadores” (CARRIJO, BOTELHO, 2013, p. 420). Vários estudos enfocam as políticas de incentivos voltadas a MPEs (CARRIJO, BOTELHO, 2013; TORRES, 2016). No entanto, nenhum deles discute as especificidades da região Centro-Oeste, dificultando os debates acerca dos resultados das políticas em nível regional. Assim, esta pesquisa tem como objetivo analisar os resultados do Pappe segundo a visão das empresas beneficiadas na região Centro-Oeste. Espera-se que tal estudo caracterize essa política de incentivo à inovação na região e verifique se a mesma tem estimulado o relacionamento do setor produtivo com agentes capazes de criar novos conhecimentos, impactando na capacidade inovativa e, consequentemente, no desenvolvimento do sistema regional de inovação.

O trabalho está estruturado em três seções, além desta introdução e das considerações finais. Na segunda seção, apresenta-se uma revisão teórica sobre sistemas de inovação e mecanismos de apoio a CT\&I no país, bem como descreve as principais características do Pappe e alguns trabalhos que avaliaram o programa. Na terceira seção, são indicados os materiais e métodos adotados na pesquisa. Na quarta seção, apresentam-se os resultados e discussões acerca das políticas de CT\&I da região em estudo,

\footnotetext{
${ }^{1}$ Lei 10.973, de 02.12.2004, regulamentada pelo Decreto 5.563, de 11/10/2005.

2 Lei 11.196, de 21.11.2005, regulamentada pelo Decreto 5.798 de 07/06/2006.
} 
particularmente, a visão das empresas selecionadas pelos editais das FAPs no que tange aos enfrentamentos para adesão ao programa, relações de cooperação e inovação antes e depois da participação, assim como os resultados atingidos.

\section{Revisão bibliográfica}

\subsection{Sistemas Nacionais de Inovação e as Políticas Públicas de apoio a CT\&I}

O processo de inovação é visto por muitos estudiosos como catalizador do desenvolvimento econômico dos países, uma vez que estimula o surgimento de novos padrões e trajetórias tecnológicas alternativas às vigentes (NELSON; WINTER, 1982). Diante de tal importância, desde o final dos anos 1990, o Brasil vem promovendo profundas reformas nas políticas de apoio à inovação (MORAIS, 2007). Atualmente, a legislação para apoio à CT\&I é constituída, principalmente, pelos fundos setoriais de ciência e tecnologia, pela Lei de Inovação (2004) e a Lei do Bem (2005) - que buscam promover a interação de universidades e institutos de pesquisa com o setor produtivo. As alterações no marco legal têm por objetivo estimular processos de modernização tecnológica nas empresas e criar ambiente institucional mais favorável ao aprofundamento da cooperação entre os agentes públicos da área de ciência e tecnologia e o setor produtivo.

Especificamente, essas medidas de apoio à inovação são muito relevantes no caso dos países em desenvolvimento, cujos Sistemas Nacionais de Inovação (SNI) ${ }^{3}$ são caracterizados como imaturos. No caso brasileiro, o SNI ainda se encontra nesse estágio de imaturidade, em que há dificuldades de se transformar conhecimento em tecnologia (ALBUQUERQUE, 1999). As relações dos agentes constituintes desse sistema são limitadas e os fluxos de conhecimento são muito restritos. Por exemplo, as instituições de pesquisa e ensino no Brasil não conseguem mobilizar contingentes de pesquisadores e financiamento suficiente para gerar conexões fortes entre as dimensões científicas e tecnológicas. Por sua vez, as firmas investem menos em P\&D, apresentam fraca capacidade de absorção de conhecimento e têm maior dificuldade para inovar. Esses padrões acabam limitando a capacidade inovativa do país (RAPINI et al., 2009). Segundo Suzigan e Albuquerque (2011), essa condição está muito relacionada à tardia industrialização do país e ao atraso na criação de instituições de ensino e pesquisa; assim como a pouca interação entre governo, universidades e empresas.

No entanto, situações de falhas sistêmicas podem ser minimizadas com um papel preponderante dos governos, através da implementação de políticas públicas para CT\&I. Estas se tornaram importantes para competitividade das empresas e sua relevância intensifica-se no que tange às empresas de pequeno e médio porte, pois problemas de aportes de capital dificultam o engajamento em atividades inovativas por empresas desses portes, sejam estas radicais ou incrementais (BOTELHO; ALMEIDA, 2012; CARRIJO; BOTELHO, 2013; ARAUJO, 2012).

As políticas públicas de CT\&I atuais caracterizam-se pela consonância com o modelo sistêmico de inovação, popularizado a partir dos anos 1990. Diferentemente dos modelos anteriores especificamente o modelo linear e o modelo de elo da cadeia, cuja ênfase estava, respectivamente, nas instituições de pesquisa e nas firmas - o modelo sistêmico considera as complexidades do processo de inovação e é condicionado por um conjunto de instituições interativas, públicas e privadas. Nessa direção, as políticas de inovação apresentam um papel relevante ao articular e remodelar as relações entre as partes do sistema (COSTA et al, 2013). Desta forma, "as políticas associadas buscam corrigir deficiências ('falhas sistêmicas') da rede de instituições e relações que dão suporte ao processo de inovação" (VIOTTI, 2003, p. 46).

Nessa perspectiva, as políticas de inovação têm ainda um papel especial diante dos contrastes regionais no processo inovativo brasileiro, muito concentrado na região Sudeste do país. Ações governamentais têm representado um caminho alternativo rumo a uma futura diminuição dessa concentração regional das atividades de CT\&I. Formas diferenciadas de apoio às Micro e Pequenas

\footnotetext{
${ }^{3}$ O SNI pode ser definido como um conjunto de instituições com diversos atores e mecanismos constituintes que interagem e articulam entre si na construção de um ambiente inovador em um país. Entre esses atores estão: as universidades e institutos de pesquisa; as firmas; instituições de ensino; o sistema financeiro capaz de apoiar o investimento inovativo; sistemas legais; governos; entre outros (LUNDVALL, 1992).
} 
Empresas (MPEs) têm sido desenvolvidas, tanto pelo mercado quanto por governos. O apoio tem objetivo de aumentar a performance inovadora e acelerar as transformações do país em direção à economia do conhecimento (MORAIS, 2007; BOTELHO; ALMEIDA, 2012).

O Quadro 1 mostra os principais programas do Ministério da Ciência e Tecnologia, conduzidos pela agência Financiadora de Estudos e Projetos (FINEP), direcionados as MPEs com foco nos incentivos fiscais.

Quadro 1: Principais mecanismos de apoio em prol à inovação empresarial no Brasil

\begin{tabular}{|c|c|c|}
\hline Mecanismos de apoio financeiro & Modalidade de apoio financeiro & Ano de criação \\
\hline Pappe Subvenção & Subvenção para custeio de inovações, via instituições estaduais e locais & 2006 \\
\hline 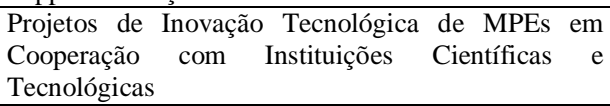 & $\begin{array}{l}\text { Apoio financeiro não reembolsável a projetos de inovação de produtos e processos } \\
\text { de MPEs, em cooperação com ICT. }\end{array}$ & 2005 \\
\hline Programa Juro-Zero & Financiamento de investimentos para Inovação, via instituição estadual & $\begin{array}{l}\text { 2004/Efetivação em } \\
2006\end{array}$ \\
\hline Projeto Inovar & $\begin{array}{l}\text { Capitalização de fundos de investimento a fim da consolidação da indústria de } \\
\text { venture capital (VC) no Brasil }\end{array}$ & 2000 \\
\hline Inova Brasil & Crédito para inovação com taxas de juros especiais & 2013 \\
\hline Prime & $\begin{array}{l}\text { Primeira Empresa Inovadora - apoia empresas inovadoras com até dois anos de } \\
\text { vida através de subsídios diretos por doze meses. }\end{array}$ & 2009 \\
\hline
\end{tabular}

Fonte: Moraes (2007); FINEP (2016).

O incentivo fiscal é um dos instrumentos mais utilizados pelos países, ao se considerar a utilização dos recursos públicos e atuação governamental, no âmbito do processo inovativo. As atividades de P\&D são foco desses incentivos, visto que envolvem um risco elevado e muitas vezes ficam comprometidas por falta de financiamentos. Por sua vez, os incentivos não fiscais priorizam outras etapas do processo inovativo, como análise de viabilidade, comercialização, desenvolvimento de protótipos voltados às MPEs e empresas de base tecnológica (RAPINI, 2010).

\subsection{Programa de Apoio à Pesquisa em Empresas (Pappe)}

O Pappe foi criado em 2003, com finalidade de atender as MPEs através de subvenção de recursos para a pesquisa e inovação que fossem realizados em conjunto com pesquisadores. Resultado da parceria entre a FINEP e as FAPs, é operacionalizado por meio de recursos federais e estaduais, no qual as FAPs ficam responsáveis por selecionar as empresas em nível estadual através de editais. Entre seus objetivos, o Pappe procura estimular a associação entre pesquisadores e empresas de base tecnológica em projetos de inovação, no intuito de favorecer as atividades de pesquisa e inovativas nas firmas. Também, o programa visa contribuir para a melhoria da distribuição geográfica dos investimentos em P\&D, buscando diminuir as disparidades regionais. (WEISZ, 2006).

De acordo com Carrijo e Botelho (2013, p. 423-424),

Em 2006, o Pappe sofreu uma modificação, com repasse de recursos diretamente às empresas, não havendo mais a necessidade de passar por um interveniente, exigência que era feita anteriormente. $\mathrm{O}$ mecanismo de apoio financeiro passou a ser ofertado às empresas por meio de subvenção econômica. Este tipo de financiamento à inovação nas empresas é muito utilizado nos países desenvolvidos e foi viabilizado no Brasil a partir da implementação da Lei de Inovação Nacional. O Programa passou a ser denominado, então, Pappe Subvenção e assumiu um direcionamento explícito às micro e pequenas empresas (MPEs), critério este definido pela Finep.

Na região Centro-Oeste, o programa teve início em 2004, no Distrito Federal, por meio da Fundação de Amparo à Pesquisa do Distrito Federal (FAPDF), lançando o segundo edital em 2008, conforme Tabela 1. Em 2010, a Fundação de Amparo à Pesquisa do Estado de Mato Grosso (FAPEMAT) operacionalizou seu primeiro edital no estado de Mato Grosso, seguido do Mato Grosso do Sul, em 2010, através da Fundação de Apoio ao Desenvolvimento do Ensino, Ciência e Tecnologia do Estado de Mato Grosso do Sul (FUNDECT). O último estado a lançar o programa foi Goiás, no ano de 2011, com a implementação via Fundação de Amparo à Pesquisa de Goiás (FAPEG), mas que repassou valor superior aos demais estados. Em contrapartida, Mato Grosso do Sul disponibilizou, em 2010, o menor repasse regional do Pappe. 
Tabela 1: Recursos disponibilizados e editais do Pappe na região Centro-Oeste, 2004-2011

\begin{tabular}{c|c|c|c}
\hline Estado & Ano & Edital & Recursos Disponibilizados (R\$) \\
\hline \multirow{2}{*}{ MT } & 2010 & $008 / 2010$ & $3.000 .000,00$ \\
\cline { 2 - 4 } & 2011 & $010 / 2011$ & $5.460 .000,00$ \\
\cline { 2 - 4 } \multirow{2}{*}{ DF } & 2004 & $06 / 2004$ & Não disponível \\
\cline { 2 - 4 } & 2008 & $11 / 2008$ & $7.500 .000,00$ \\
\hline GO & 2011 & $01 / 2011$ & $16.500 .000,00$ \\
\hline MS & 2010 & $14 / 2010$ & $2.000 .000,00$
\end{tabular}

Fonte: FAPEMAT (2010; 2011); FAPDF (2004; 2008); FAPEG (2011); FUNDECT (2010), valores nominais.

Em trabalho pioneiro na área, Carrijo e Botelho (2013) analisaram o Pappe focando na caracterização das atividades inovativas das empresas e nas relações de cooperação entre empresas e instituições de pesquisa, através de dados obtidos com a aplicação de questionários nos estados de Minas Gerais, Rio de Janeiro e São Paulo. Pela análise das respostas, as autoras conseguiram traçar um perfil das empresas participantes do programa - empresas jovens, de pequeno porte, com maior atuação no território nacional, sócios fundadores oriundos de atividades acadêmicas, entre outras características. Também, foi possível perceber que as relações de cooperação já eram realizadas de forma ampla antes das firmas participarem do Pappe, especialmente com clientes/consumidores, universidades e institutos de pesquisa do país. Nesse sentido, não se verificaram novas relações de parceria estabelecidas entre as empresas e outros agentes econômicos após sua entrada no programa, indicando que este não fomentou novas parecerias, e sim, a manutenção daquelas já em vigor. Como principais resultados oriundos do Pappe, as autoras destacaram: geração de novos produtos no mercado nacional; novos processos tecnológicos; geração de emprego; inserção em novos mercados; publicação de artigos; e geração de patentes no estado de São Paulo.

Torres (2016) avaliou às contribuições do programa através de uma pesquisa em âmbito nacional intitulada "Interações Pappe". Tal pesquisa coletou dados em diferentes estados em duas etapas: através de um questionário online aplicado às empresas participantes do programa e de entrevista estruturada com cinco das empresas respondentes da primeira fase. Entre os resultados da pesquisa, percebeu-se que as empresas participantes são relativamente jovens e cooperativas, tendo fortalecido suas parcerias através dos projetos aprovados no programa, especialmente com fornecedores, clientes e universidades. Diferentemente do que apontam os estudos da Pesquisa de Inovação Tecnológica (PINTEC/IBGE), entre os principais resultados do programa tem-se uma predominância das inovações de produto sobre as inovações de processo. Ademais, o estudo mostrou que as principais dificuldades enfrentadas pelas empresas para o desenvolvimento do projeto estão relacionadas à falta de mão de obra qualificada e a demora na liberação dos recursos financeiros.

Outros trabalhos analisaram os resultados do Pappe em Minas Gerais, Alagoas, Pernambuco e Manaus (LIMA et al., 2013; LIMA et al., 2015; AQUINO, 2013; SILVA et al., 2009). No geral, estes estudos enfatizaram a importância do programa como mecanismo governamental de apoio às empresas para a promoção de inovações e aumento de competitividade. Ainda, em alguns casos, se verificou os limites e dificuldades do programa em relação aos processos burocráticos, cronogramas, resultados obtidos e atendimento aos objetivos gerais propostos no Pappe (LIMA et al., 2015, AQUINO, 2013).

\section{Materiais e métodos}

A presente pesquisa ampara-se em metodologia de pesquisa de natureza quantitativa e qualitativa, com estrutura básica de investigação descritiva. As estratégias de pesquisa quanto ao local da coleta de dados e fontes de informação, bem como seus delineamentos para análise das políticas públicas de CT\&I, estão divididas em duas partes. Na primeira parte, foi realizado um levantamento dos indicadores tecnológicos da Região Centro-Oeste, através de fontes de dados secundários. Foram coletados dados referentes aos esforços tecnológicos das firmas, particularmente, as características das atividades inovativas segundo a PINTEC e os registros de patentes junto ao Instituto Nacional de Propriedade Industrial (INPI), bem como dos gastos com CT\&I no Brasil, na região e nas localidades em estudo, retirados do site do Ministério de Ciência e Tecnologia (MCT). A análise abrangeu diversos anos a partir do ano 2000. 
A segunda parte da pesquisa traz a avaliação dos resultados do Pappe no Centro-Oeste, a partir da visão das empresas beneficiadas pelo programa com recursos de subvenção direcionados à inovação. Para o mapeamento, realizou-se pesquisa documental de informações, sobretudo os editais lançados pelas FAPs e seus respectivos resultados, cuja divulgação é publicada na internet ${ }^{4}$. Para avaliação do programa, utilizou-se questionário elaborado por Carrijo e Botelho (2013), que realizou pesquisa equivalente na região Sudeste. Para coleta de dados primários junto às firmas investigadas, durante o segundo semestre de 2013, foi oferecida as firmas a opção de responder o questionário na forma digital ou por entrevista via telefone.

Estipulou-se que seriam pesquisadas as empresas beneficiadas por editais até o ano de 2011, devido ao tempo necessário para implantar o projeto, que é cerca de dois anos. A pretensão inicial seria investigar todas as empresas, mas algumas se negaram a participar, enquanto outras foram excluídas da amostra porque seus projetos não estavam concluídos. Assim, entre os anos de 2004 e 2011, foram contempladas 119 MPEs da região Centro-Oeste, das quais 19 participaram da pesquisa, conforme Tabela 2.

Tabela 2: População e amostra das empresas beneficiadas pelo Pappe, região Centro-Oeste, 2004-2011

\begin{tabular}{l|c|c|c}
\hline Estado & Ano do Edita do Pappe & $\begin{array}{c}\text { Empresas beneficiadas - população } \\
\text { (\% em relação ao total da região) }\end{array}$ & $\begin{array}{c}\text { Número de empresas que responderam o } \\
\text { questionário - amostra } \\
\text { (\% em relação a população) }\end{array}$ \\
\hline Mato Grosso & 2009,2011 ou ambos & $28(23,5 \%)$ & $5(17,9 \%)$ \\
\hline Mato Grosso do Sul & 2010 & $11(9,2 \%)$ & $2(18,2 \%)$ \\
\hline Goiás & 2011 & $39(32,8 \%)$ & $8(20,5 \%)$ \\
\hline Distrito Federal & 2004,2008 ou ambos & $41(34,4 \%)$ & $4(9,8 \%)$ \\
\hline Total - região & vários & $119(100 \%)$ & $19(16,0 \%)$ \\
\hline
\end{tabular}

Fonte: Survey com empresas (2013).

O Distrito Federal, além de precursor na adesão ao Programa em 2004, também teve o maior número de empresas beneficiadas, equivalente a 34,4\% do total. O estado de Goiás, embora tenha oferecido apenas um edital no período analisado, ocupa a segunda posição no que tange a quantidade de empresas beneficiadas, com 32,8\%, seguido do Mato Grosso, com 23,5\%, e Mato Grosso do Sul, com 9,2\%. No total, a amostra abrangeu 19 empresas, que corresponde a 16\% do total, e destas, 8 estão instaladas em Goiás, 5 no Mato Grosso, 4 no Distrito Federal e 2 no Mato Grosso do Sul.

\section{Resultados e discussões}

\subsection{Indicadores de CT\&I na Região Centro-Oeste}

As disparidades regionais brasileiras de CT\&I refletem a hierarquia dos demais indicadores de desenvolvimento socioeconômico, com forte concentração das bases científicas, tecnológicas e dos gastos governamentais com CT\&I nas regiões Sudeste e Sul (CAVALCANTE, 2011; FONSECA, 2012). Por sua vez, estudos sobre o sistema de CT\&I da região Centro-Oeste destacam o hiato científico e tecnológico desta em relação às outras regiões do país. De acordo com Almeida et. al. (2011, p. 107-108), a região caracteriza-se

[...] (i) pela baixa representatividade na produção científica nacional; (ii) taxa muito pequena de investimento em CT\&I em relação ao cenário nacional, (iii) debilitada infraestrutura científicotecnológica, baseada na retraída mobilização de instituições públicas ou privadas quanto as atividades de pesquisa; e (iv) baixa oferta de cursos de pós-graduação, sobretudo no Mato Grosso e Mato Grosso do Sul.

\footnotetext{
${ }^{4}$ Na região, atuam as seguintes instituições: Fundação de Amparo à Pesquisa do Estado de Mato Grosso (FAPEMAT), Fundação de Amparo à Pesquisa do Estado de Goiás (FAPEG), Fundação de Amparo e Pesquisa do Distrito Federal (FAPDF), Fundação de Apoio ao Desenvolvimento do Ensino, Ciência e Tecnologia do Estado de Mato Grosso do Sul (FUNDECT). A colaboração das FAPs foi importante para confirmar o número de editais e as informações coletadas via dados secundários, em especial da FAPDF - pela disponibilização das páginas do Diário Oficial do Distrito Federal (DODF), onde se encontrava os resultados de editais - e da FAPEMAT, que inclusive encaminhou a lista de empresas beneficiadas, com seus respectivos emails.
} 
Contudo, nos anos 2000, observou-se convergência regional e interestadual das bases científicas, através de superior taxa de crescimento do número de pesquisadores doutores residentes das localidades menos desenvolvidas (CAVALCANTI, 2011). Por sua vez, a região Centro-Oeste, o aumento de pesquisadores doutores nos anos 2000 foi acima da média nacional, equivalente a 207,82\% em 2010, em relação a 2002, enquanto no Brasil a taxa foi de 137,92\% (ALMEIDA et. al., 2011).

Sobre as possíveis externalidades positivas da concentração de recursos humanos qualificados em determinadas regiões geográficas, Cavalcante (2011, p. 21) explica que

\begin{abstract}
Não se trata, aqui, de negar a existência de escalas mínimas de produção científica que tendem, efetivamente, a criar aglomerações regionais da base científica. Em certo sentido, poderia ser saudável a existência de centros regionais de excelência. Essa proposição, entretanto, parece razoável se os dados são segmentados por áreas do conhecimento. Nesse caso, há recorrentes evidências de concentração regional mesmo em países bastante homogêneos. No Brasil, opostamente, as desigualdades da base científica observadas referem-se ao total do número de doutores. Não se trata, assim, de diferentes vocações regionais, mas de uma efetiva disparidade regional.
\end{abstract}

Assim, dado o reconhecimento que a "apropriação do progresso técnico em diversos pontos do território nacional” é importante para o desenvolvimento econômico nacional (FONSECA, 2012, p. 3), bem como para a sustentação das políticas de atração de investimentos para regiões periféricas (CAVALCANTE, 2011), nos anos 2000, tanto o governo federal, quanto os estados, tomaram iniciativas para maior distribuição dos recursos em CT\&I. Assim, em 2007, o Ministério de Ciência e Tecnologia (atual MCTI) criou o Plano de Ação em Ciência, Tecnologia e Inovação (PACTI), com objetivo de "mobilizar e articular ações do Governo Federal em cooperação com os governos municipal, estadual e distrital” (FONSECA, 2012, p. 2). Dentre seus resultados, tem-se o aumento de $45 \%$ nos valores de bolsas do CNPq concedidos em 2010, em comparação a 2007, bem como a desconcentração territorial desses investimentos, com

aumento da participação relativa da região Norte e Nordeste e queda da região Sudeste no total dos investimentos. [...] A região Norte evolui cerca de 55\% no período, seguida da região Nordeste, com avanço de $51 \%$. A região Sudeste teve um aumento de $28 \%$ na concessão de bolsas no mesmo período. (FONSECA, 2012, p. 19).

Sob direcionamento das políticas federais, muitos governos estaduais fortaleceram suas Fundações de Amparo à Pesquisa ${ }^{5}$, contribuindo para redução de desigualdades a partir do aumento significativo dos investimentos em C\&T em relação à receita total, bem como o aumento da proporção desses investimentos em P\&D. Na região Centro-Oeste, até 2006, apenas cerca de $0,2 \%$ do valor arrecado foi destinado a C\&T, chegando ao patamar de 0,07\% em 2002, de acordo com a Tabela 3. Após 2008, esses valores vêm crescendo, atingindo 0,96\% em 2012, refletindo as variações das unidades federativas (UFs), salvo o caso de Goiás, que apresentava valores altos e comparação aos demais no início da década, oscilando e atingindo valores muito baixos entre 2002 e 2010. No mesmo período, essa proporção tem-se mantido estável no Brasil, com diminuição progressiva entre 2002 e 2006, seguido de um aumento a partir de 2007, chegando no seu maior percentual no ano de 2012 (2,16\%). Os maiores percentuais são das regiões Sudeste e Sul, sendo que primeiro atinge 3\% dos gastos estaduais em alguns dos anos selecionados.

Tabela 3: Participação percentual do dispêndio dos governos estaduais em C\&T em relação à receita total, Brasil, Grandes Regiões e Unidades da Federação da Região Centro-Oeste, 2000-2013

\begin{tabular}{|c|c|c|c|c|c|c|c|c|c|c|c|c|c|c|}
\hline $\begin{array}{l}\text { Regiões e Unidades } \\
\text { da Federação }\end{array}$ & 2000 & 2001 & 2002 & 2003 & 2004 & 2005 & 2006 & 2007 & 2008 & 2009 & 2010 & 2011 & 2012 & 2013 \\
\hline Brasil & 1,87 & 1,96 & 1,83 & 1,77 & 1,63 & 1,46 & 1,40 & 1,66 & 1,70 & 1,89 & 1,99 & 2,10 & 2,16 & 1,94 \\
\hline Norte & 0,27 & 0,23 & 0,19 & 0,24 & 0,24 & 0,33 & 0,53 & 0,56 & 0,66 & 0,96 & 1,06 & 0,90 & 0,96 & 0,90 \\
\hline Nordeste & 0,51 & 0,68 & 0,62 & 0,72 & 0,69 & 0,75 & 0,74 & 0,79 & 0,95 & 1,10 & 1,31 & 1,16 & 1,27 & 1,00 \\
\hline Sudeste & 3,10 & 3,20 & 3,09 & 2,84 & 2,53 & 2,16 & 2,02 & 2,46 & 2,43 & 2,61 & 2,68 & 2,97 & 3,02 & 2,87 \\
\hline Sul & 1,08 & 1,25 & 1,22 & 1,14 & 1,24 & 1,25 & 1,26 & 1,27 & 1,43 & 1,68 & 1,69 & 1,72 & 1,82 & 1,50 \\
\hline
\end{tabular}

\footnotetext{
${ }^{5}$ Na região em estudo, a FAPEMAT foi fundada em 1997; FUNDECT em 1999; FAPEG, 2005; e FAPDF, 1993.
} 


\begin{tabular}{l|l|l|l|l|l|l|l|l|l|l|l|l|l|l} 
Centro-Oeste & 0,28 & 0,21 & 0,07 & 0,12 & 0,26 & 0,28 & 0,27 & 0,48 & 0,42 & 0,69 & 0,80 & 0,82 & 0,96 & 0,84 \\
\hline Distrito Federal & 0,05 & 0,05 & 0,02 & 0,06 & 0,20 & 0,19 & 0,17 & 0,79 & 0,44 & 1,16 & 1,33 & 0,95 & 0,97 & 0,92 \\
\hline Goiás & 0,99 & 0,63 & 0,10 & 0,08 & 0,12 & 0,14 & 0,13 & 0,28 & 0,28 & 0,34 & 0,32 & 0,65 & 0,87 & 0,71 \\
\hline Mato Grosso & 0,05 & 0,05 & 0,07 & 0,12 & 0,59 & 0,61 & 0,62 & 0,55 & 0,73 & 0,91 & 1,06 & 1,23 & 0,95 & 0,85 \\
\hline Mato Grosso do Sul & 0,06 & 0,07 & 0,13 & 0,27 & 0,20 & 0,25 & 0,25 & 0,22 & 0,25 & 0,23 & 0,49 & 0,42 & 1,08 & 0,95 \\
\hline
\end{tabular}

Fonte: MCTI.

Em valores monetários, os governos estaduais investiram cerca de R\$ 15 bilhões em C\&T em 2013, dos quais 73,2\% foram destinados as atividades de P\&D, como demonstrado na Figura 1. Como esperado, tanto no ano 2000, quanto em 2013, esse também é o padrão das regiões Sudeste e Sul. Embora predomine os gastos com Atividades Correlatas Técnico Científicas (ACTC), a região Centro-Oeste tem aumentado os gastos em Pesquisa e Desenvolvimento (P\&D), aplicando 32,5\% dos seus recursos em P\&D em 2013, contra 3,7\% em 2000. O aumento da proporção dos recursos para P\&D foi verificado em todas as UFs da região, com exceção do estado de Mato Grosso. Portanto, apesar da tendência de aumento no período analisado, os governos estaduais das regiões periféricas, entre elas, a região CentroOeste, investem em C\&T e em P\&D percentuais abaixo da média brasileira.
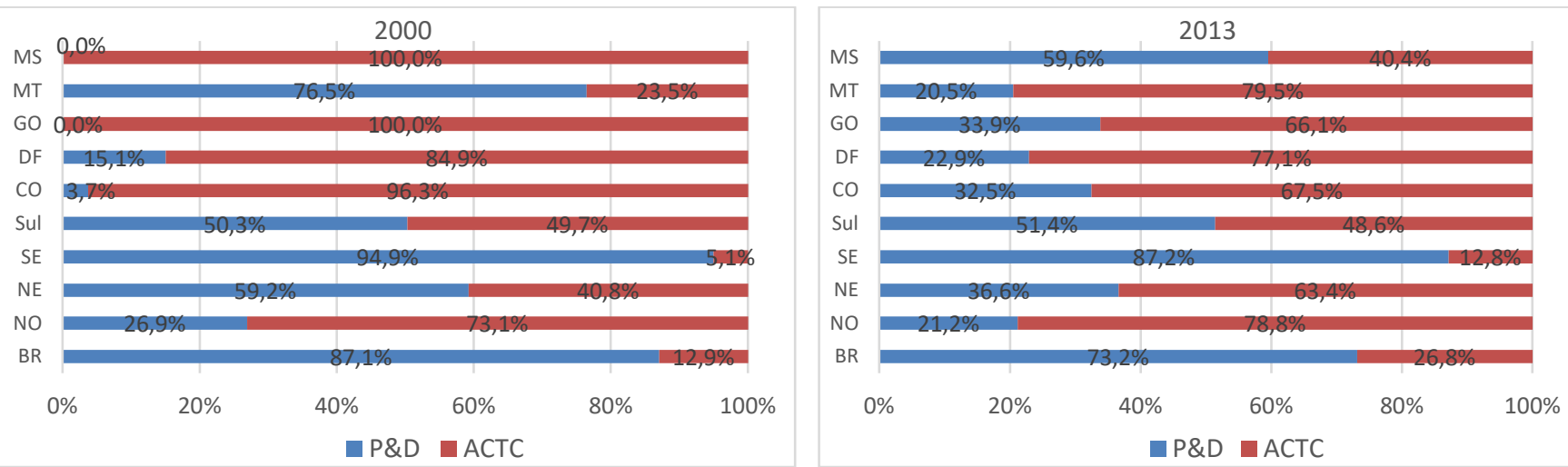

Figura 1: Dispêndios totais dos governos estaduais em C\&T por modalidade (P\&D e ACTC), Brasil, Grandes Regiões e Unidades da Federação da Região Centro-Oeste, 2000 e 2013 (em \%)

Notas: Os dispêndios dos governos estaduais em C\&T dividem-se em P\&D e ACTC.

Fonte: MCTI.

As iniciativas dos governos estaduais quanto ao aumento dos gastos e o fortalecimento da base científica não têm sido suficientes para uma resposta mais ativa do setor empresarial. Como apresentado por Cavalcante (2011), isso não tem sido uma situação isolada do Centro-Oeste. O autor analisou a evolução do pessoal ocupado técnico-científico entre 2000 e 2008 através de indicador de desigualdade (índice de Theil), concluindo que a convergência da base científica não foi acompanhada de redução de desigualdades da base tecnológica entre 2000 e 2008.

No que tange aos esforços tecnológicos das empresas, os dados da PINTEC apontam um aumento significativo no número de empresas que implantaram inovações de produto ou processo produtivo em todas as regiões do Brasil entre os triênios 2000-2003 e 2009-2011, conforme Tabela 4. No Centro-Oeste, a participação de firmas inovadoras no total das empresas das indústrias extrativa e de transformação passou de 31,7\% para 39,4\%, crescimento acima da média nacional. Do total de firmas que inovaram, 1,7\% daquelas instaladas na região realizaram P\&D no triênio 2000-2003, subindo para 3\% em 20092011, crescimento insuficiente para alcançar a média nacional, de 5\%. Cabe ressaltar que das 200 empresas com laboratório de P\&D entre 2009-2011, 158 estavam instaladas em Goiás e 7 em Mato Grosso, evidenciando ainda desigualdades intrarregionais. 
Tabela 4: Esforços inovativos das empresas das indústrias extrativa e de transformação, Brasil, Grandes Regiões e Unidades da Federação da Região Centro-Oeste, 2000-2003 e 2009-2011

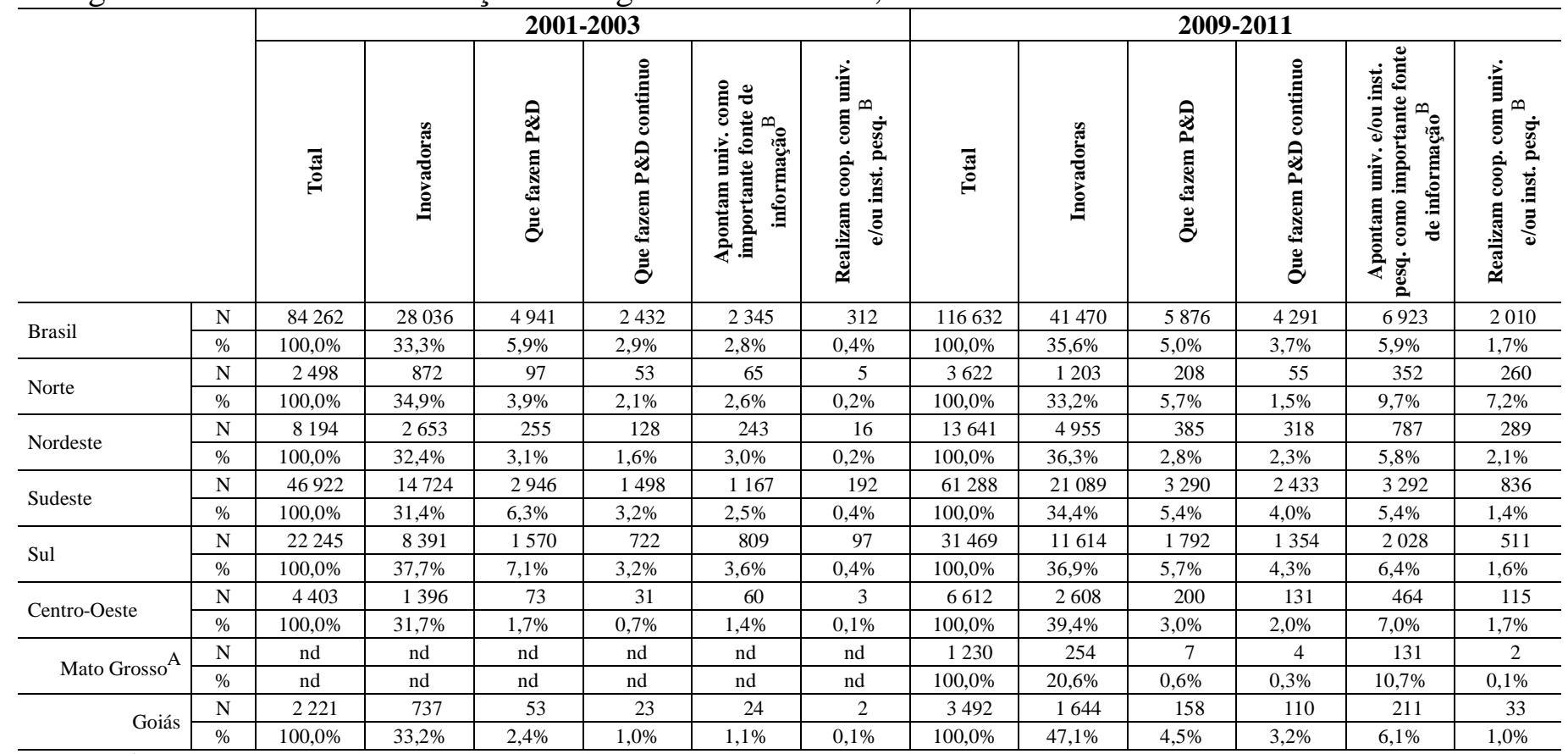

Nota: ${ }^{\mathrm{A}}$ Antes o triênio 2009-2011, os dados levantados englobavam a região Centro-Oeste e somente o estado de Goiás separadamente. ${ }^{\mathrm{B}}$ As empresas atribuíram média ou alta importância para as instituições mencionadas.

Fonte: IBGE-PINTEC (2003; 2011). Elaboração do autor.

Apesar de não suficiente para alcançar patamares das regiões mais desenvolvidas, os esforços das empresas instaladas na região Centro-Oeste têm alterado a distribuição das atividades inovativas no país a favor da mesma. Em 2000-2003, a região respondia por 5,23\% das empresas do setor industrial do país, atingindo 5,67\% em 2009-2011. No caso das empresas inovadoras, a participação elevou-se de 4,98\% para 6,29\%, dobrando sua participação nas que realizam P\&D e P\&D contínuo, como demonstrado na Figura 2.

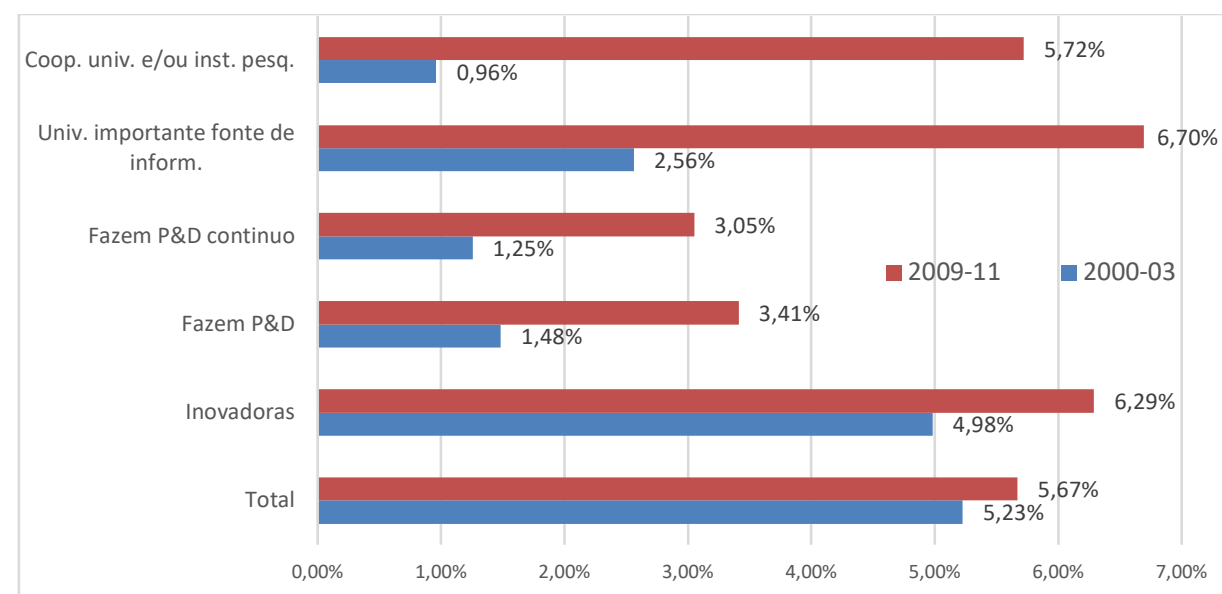

Figura 2: Participação das empresas das indústrias extrativa e de transformação da região Centro-Oeste no total do país segundo esforços inovativos, 2000-2003 e 2009-2011

Fonte: IBGE-PINTEC (2003; 2011). Elaboração do autor.

Quanto a relação com universidades e institutos de pesquisa, o percentual de firmas da região que apontaram universidades como fontes de informação relevante para atividades de inovação, aproximadamente 7\% em 2009-2011, está acima da média nacional de 5\% (Tabela 4). Nesse caso, também houve redistribuição a favor da região: em termos de participação no total de firmas do país, o Centro-Oeste passou a responder por 6,7\%, contra 2,56\% em 2000-2003 (Figura 2). O mesmo ocorreu 
com o número de firmas que declararam realizar cooperação com universidades e institutos de pesquisa, que aumentou de $0,96 \%$ para $5,72 \%$.

As patentes requeridas junto ao INPI também servem como proxy dos esforços tecnológicos das firmas. A Figura 3 mostra o total de patentes requeridas por residentes nos intervalos 2000-2006 e 20072015. Em consonância com a hierarquia dos demais indicadores tecnológicos, as empresas da região Sudeste respondem por cerca e $60 \%$ das patentes do país, seguida da região Sul (26\%) e Nordeste (7\%). O Centro-Oeste aumentou ligeiramente sua participação, de 4,1\% para 4,5\%, totalizando uma soma de 3.048 patentes registradas entre 2007 e 2015.
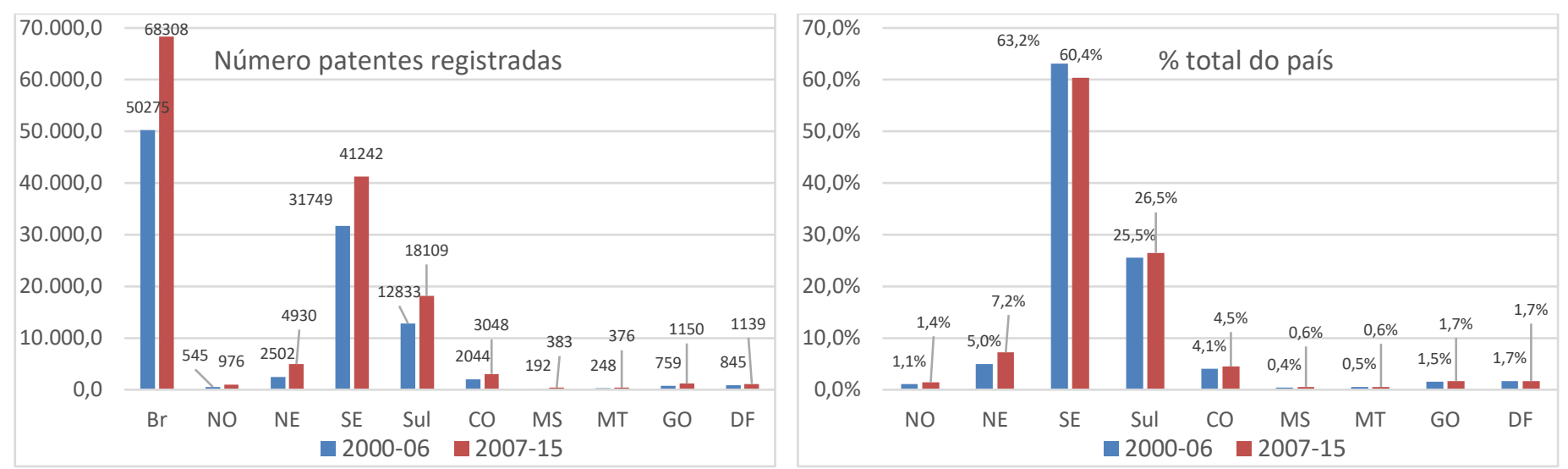

Figura 3: Depósitos de patentes registrados junto ao INPI, Brasil, Grandes Regiões e Unidades da Federação da Região Centro-Oeste, 2008 - 2014

Fonte: MCTI. Elaboração do autor.

Novamente, observa-se desigualdades intrarregionais, com forte concentração de patentes oriundas de Goiás e do Distrito Federal, o que está relacionado não somente aos esforços de P\&D concentração em Goiás, como visto na Tabela 4 -, como também se vincula as diferenças das estruturas produtivas entre os estados, pois Goiás apresenta economia mais diversificada no que tange a indústria de transformação, enquanto em Mato Grosso e Mato Grosso do Sul sobressaem-se as atividades relacionadas ao agronegócio. (ALMEIDA et. al., 2011). Tal afirmação encontra respaldo em estudo de Montenegro et. al. (2014, p. 14) sobre efeitos de externalidades de diversificação e especialização produtiva, que observou que "quanto mais diversificado for a estrutura produtiva do Estado, espera-se que haja maior capacidade de desenvolvimento de C\&T na região”.

Dessa forma, tem-se que os indicadores de CT\&I da região Centro-Oeste mostram fortalecimento da base científica, a partir da criação de novos cursos, contratação de doutores pelas instituições de ensino e pesquisa e aumento dos gastos dos governos estaduais. Também foram observados avanços nos esforços tecnológicos, aumentando a participação das firmas da região no total de empresas inovadoras, porém, tais empenhos não foram refletidos no total de patentes. Como apontado por Cavalcante (2001, p. 26), "as regiões menos desenvolvidas não somente têm uma menor base científica como contam com mecanismos de transmissão mais precários entre a ciência e a tecnologia”. No caso da região em estudo, pode-se afirmar que, dentre tais fatores, tem-se a fraca interatividade academia-indústria. Como relatado por Almeida et. al. (2011, P. 108), em estudo sobre grupos e empresas interativas na região,

Esse aspecto é explicado, por um lado, pela baixa demanda por tecnologia por parte das empresas, diante dos escassos esforços tecnológicos e em virtude da própria especialização regional, baseada em produtos de baixo valor agregado, que não incentiva a busca de conhecimento junto as universidade e institutos de pesquisa. Por outro, contribui também o tardio início das atividades de pesquisa na região, uma vez que as universidades federais e estaduais somente recentemente têm se voltado para a problemática de realizar pesquisa conjunta com o setor privado.

Dessa maneira, sobressaem as interações entre os grupos da área de ciências agrárias e empresas ligadas ao agronegócio.

Por fim, dada a fragilidade dos mecanismos de transmissão de conhecimento, cabe ressaltar que a presente análise não permite atribuir a intensificação das atividades inovativas das firmas a convergência 
da base científica e ao aumento dos gastos públicos estaduais. Uma possibilidade é que tais esforços tenham decorrido de fatores competitivos de seus respectivos mercados, bem como da instalação, nos anos 2000, de empresas ligadas ao setor agroindustrial. Quanto ao fato das atividades inovativas não aumentarem o registro de patentes, qualquer consideração requer aprofundamento mediante recorte setorial, visto que a apropriabilidade das inovações é mais importante em determinados segmentos do que em outros.

\subsection{Resultados do Programa de Apoio à Pesquisa em Empresas (Pappe): Survey das Empresas da Região Centro-Oeste}

\subsubsection{Características das empresas e sócios entrevistados}

A Tabela 5 traz as principais características das empresas com projetos aprovados no Pappe na região Centro-Oeste. A maior parte das empresas (13) foi fundada nos anos 2000, sendo que apenas 4 empresas iniciaram suas atividades nos anos 1990 e 2 antes entre 1960 e 1980. Considerando o porte das empresas, evidentemente todas as empresas participantes classificam-se como MPEs, pois estas são alvo do programa. Assim, tem-se que 9 empresas são micro e 10 são de pequenas. Em relação ao mercado de atuação, 10 empresas tem o mercado nacional como um dos principais destinos das vendas, 9 declararam o mercado estadual e 6 o local.

Tabela 5: Características das empresas com projetos aprovados no Pappe, Região Centro-Oeste, 2013

\begin{tabular}{|c|c|c|c|c|c|}
\hline Características & Número & $\%$ & Características & Número & $\%$ \\
\hline \multicolumn{3}{|l|}{ Fundação } & \multicolumn{3}{|c|}{ Mercado de atuação $^{B}$} \\
\hline Anos 60 & 1 & $5,3 \%$ & Local & 6 & $31,6 \%$ \\
\hline Anos 80 & 1 & $5,3 \%$ & Estadual & 9 & $47,4 \%$ \\
\hline Anos 90 & 4 & $21,1 \%$ & Nacional & 10 & $52,6 \%$ \\
\hline Anos 2000 & 13 & $68,4 \%$ & Total de respostas & 25 & $131,6 \%$ \\
\hline \multicolumn{3}{|l|}{ Porte empresarial $^{\mathrm{A}}$} & \multicolumn{3}{|l|}{ Setor } \\
\hline Micro & 9 & $47,4 \%$ & Tecnologia & 12 & $63,2 \%$ \\
\hline \multirow[t]{2}{*}{ Pequena } & 10 & $52,6 \%$ & Indústria & 7 & $36,8 \%$ \\
\hline & & & Florestal & 1 & $5,3 \%$ \\
\hline Total de empresas & \multicolumn{5}{|c|}{19} \\
\hline
\end{tabular}

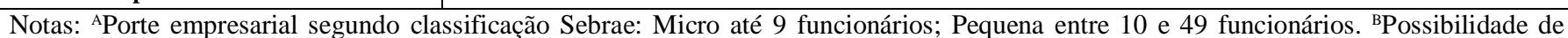
marcar mais de uma opção no item "mercado de atuação".

Fonte: Survey com empresas (2013).

Em termos de atividade econômica, 12 empresas são do segmento de tecnologia, atuando nas áreas de tecnologia da informação e criação de softwares para serviços industriais, 7 empresas pertencem ao setor industrial, atuando nos segmentos automobilístico, plástico, fármacos, produção de equipamentos industriais, entre outros. Apenas uma empresa é do setor de reflorestamento e beneficiamento de madeira.

No que tange aos recursos humanos da empresa, há um total de 210 entre funcionários e sócio. Desses, 63,3\% possuem superior completo ou pós-graduação, em decorrência do setor de atuação da maioria das firmas, ligado a tecnologia. Além disso, 72\%, que equivalente a um número de 187 empregados, tem vínculos formais com as empresas entrevistadas, segundo Figura 4.
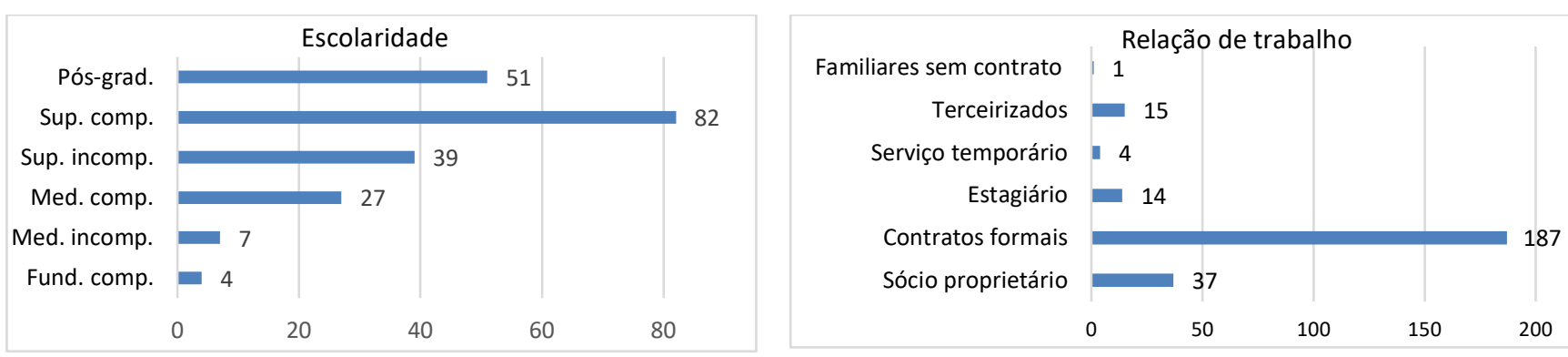

Figura 4: Distribuição do pessoal ocupado nas empresas com projetos aprovados no Pappe, segundo grau de escolaridade e relação de trabalho Região Centro-Oeste, 2013 
As características dos sócios fundadores são identificadas na Tabela 6. A idade dos sócios no momento de fundação da empresa distribui-se igualmente entre as três faixas etárias: entre 20 e 30 anos, 31 a 40 anos e 41 a 50 anos. Em termos de escolaridade, 3 possuíam ensino médio completo ou incompleto, 7 nível superior completo ou incompleto e 9 pós-graduação. Assim como no caso dos funcionários, o nível educacional acima da média nacional vincula-se a atividade econômica da maioria das firmas (tecnologia).

Tabela 6: Características dos sócios fundadores das empresas com projetos aprovados no Pappe, Região Centro-Oeste, 2013

\begin{tabular}{|c|c|c|c|c|c|}
\hline Características & Número & $\%$ & Características & Número & $\%$ \\
\hline \multicolumn{3}{|l|}{ Idade } & \multicolumn{3}{|l|}{ Sexo } \\
\hline De 20 a 30 anos & 6 & $31,58 \%$ & Feminino & 3 & $16,00 \%$ \\
\hline De 31 a 40 anos & 6 & $31,58 \%$ & Masculino & 16 & $84,00 \%$ \\
\hline De 41 a 50 anos & 6 & $31,58 \%$ & Total de respostas & 19 & $100 \%$ \\
\hline Várias idades & 1 & $52,60 \%$ & \multicolumn{3}{|l|}{ Pais eram empresários } \\
\hline Total de respostas & 19 & $100 \%$ & Sim & 5 & $26,32 \%$ \\
\hline \multicolumn{3}{|c|}{ Escolaridade quando criou a empresa } & \multicolumn{3}{|c|}{ Atividade antes de fundar a empresa } \\
\hline Ensino médio incompleto & 2 & $10,53 \%$ & Estudante Universitário & 2 & $10,53 \%$ \\
\hline Ensino médio completo & 1 & $5,26 \%$ & $\begin{array}{l}\text { Empregado de empresa local ou } \\
\text { multinacional }\end{array}$ & 8 & $42,11 \%$ \\
\hline Superior incompleto & 2 & $10,53 \%$ & Funcionário de inst. pública & 1 & $5,26 \%$ \\
\hline Superior completo & 5 & $26,32 \%$ & Empresário & 5 & $26,32 \%$ \\
\hline Pós-graduação & 9 & $47,37 \%$ & Outra atividade não informada & 3 & $15,79 \%$ \\
\hline Total de respostas & 19 & $100 \%$ & Total de respostas & 19 & $100 \%$ \\
\hline
\end{tabular}

Nota: Possibilidade de marcar mais de uma opção no item "atividade do sócio fundador antes da criação da empresa”.

Fonte: Survey com empresas (2013).

Predomina o gênero masculino entre sócios, com apenas 3 mulheres como fundadoras das empresas entrevistadas. Por sua vez, somente 5 empresas foram fundadas por sócio cujos pais eram empresários, contudo, a maioria já trabalhava no setor empresarial, sendo 5 empresários e 8 empregados de empresa privada local ou multinacional.

Assim como no trabalho de Carrijo e Botelho (2012), percebe-se a predominância de empresas jovens, de pequeno porte e com atuação no território nacional. Porém, no caso do Centro-Oeste, no geral, os sócios fundadores das empresas são oriundos do próprio setor empresarial, poucos oriundos do setor acadêmico, em consonância com a base científica regional, caracterizada por poucos cursos de pósgraduação, dificultando o surgimento de spin-offs.

\subsubsection{Adesão ao Pappe}

No campo da adesão das empresas ao Pappe, o maior estímulo para que as empresas submetessem projetos foi a possibilidade de obter recursos de subvenção econômica (11 firmas), de acordo com a Tabela 7. Isso reafirma o que tem sido apresentado em outros trabalhos, em que as MPEs, em virtude de sua menor estrutura de capital, não costumam utilizar de recursos financiados a taxas de juros de mercado ou capital de risco para promover inovações, cujo risco é inerente ao processo (MORAIS, 2007; ARAUJO, 2012; BOTELHO; ALMEIDA, 2012).

Na sequência, 8 empresas responderam que submeteram projetos porque o edital cumpria os objetivos da empresa ou porque já participavam de outros editais. Isso indica que empresas que já participaram de algum projeto tendem a ter maior possibilidade de concorrer a outros editais, o que pode estar relacionado com um processo de aprendizagem de redigir projetos e atender as exigências das instituições de fomento, como demonstrado também em Carrijo e Botelho (2013).

Neste contexto é preciso destacar que das empresas entrevistadas, 14 participaram de um edital e 5 participaram de 2 editais. Levando em consideração que, durante o período analisado, os estados de Goiás e Mato Groso do Sul ofereceram apenas 1 edital, enquanto o Distrito Federal e o Mato Grosso ofereceram 2 editais, esse resultado confirma a hipótese do aprendizado cumulativo necessário para submeter projetos. 
Tabela 7: Adesão das empresas ao Pappe segundo características diversas, Região Centro-Oeste, 2013

\begin{tabular}{|c|c|c|}
\hline Características & $\mathbf{N}^{\mathbf{0}}$ & $\%$ \\
\hline \multicolumn{3}{|l|}{ Porque a empresa optou por participar do Pappe $^{\mathrm{A}}$} \\
\hline Porque o edital Pappe é menos exigente & 2 & $11 \%$ \\
\hline Porque a empresa não conhece outro programa de apoio & 1 & $5 \%$ \\
\hline $\begin{array}{l}\text { Porque o edital atende meus objetivos e já participo de outros editais de outras instituições de } \\
\text { fomento }\end{array}$ & 8 & $42 \%$ \\
\hline Porque são recursos de subvenção & 11 & $58 \%$ \\
\hline Total de respostas & 22 & - \\
\hline Total de empresas & 19 & $100 \%$ \\
\hline \multicolumn{3}{|l|}{ Como tomou conhecimento do Pappe } \\
\hline Site da FAP & 4 & $21 \%$ \\
\hline Divulgação em jornais, sites de notícias & 4 & $21 \%$ \\
\hline No ambiente acadêmico & 2 & $11 \%$ \\
\hline Por meio de associações, entidades de representação, órgãos de apoio e promoção & 7 & $37 \%$ \\
\hline Outros & 2 & $11 \%$ \\
\hline Total de empresas & 19 & $100 \%$ \\
\hline \multicolumn{3}{|l|}{ Quantidade de projetos aprovados pelo Pappe } \\
\hline Apenas um & 14 & $74 \%$ \\
\hline Dois & 5 & $26 \%$ \\
\hline Total de empresas & 19 & $100 \%$ \\
\hline
\end{tabular}

Nota: APossibilidade de marcar mais de uma opção.

Fonte: Survey com empresas (2013).

As empresas tomaram conhecimento do programa especialmente através de associações, entidades de representação, órgãos de apoio e promoção, seguidas de divulgações no próprio site da FAP e em jornais e site de notícias. Somente duas empresas tomaram conhecimento no ambiente acadêmico (Tabela 7).

As empresas apresentaram opiniões divergentes em relação as dificuldades enfrentadas para se adequar as exigências da FAP, conforme Tabela 8. Porém, o principal problema encontrado para submeter projeto ao edital foi fazer o estudo de viabilidade técnica econômica e comercial, considerado de média ou alta relevância por 13 firmas, equivalente a 68,4\% do total.

Tabela 8: Dificuldades para se adequar às exigências da FAP para submeter um projeto ao edital do Pappe segundo grau de relevância, Região Centro-Oeste, 2013

\begin{tabular}{|c|c|c|c|c|c|c|c|c|}
\hline \multirow{2}{*}{ Dificuldades } & \multicolumn{2}{|c|}{ Não relevante } & \multicolumn{2}{|c|}{ Baixa relevância } & \multicolumn{2}{|c|}{ Média relevância } & \multicolumn{2}{|c|}{ Alta relevância } \\
\hline & $\mathbf{N}^{\mathbf{0}}$ & $\%$ & $\mathbf{N}^{0}$ & $\%$ & $\mathbf{N}^{0}$ & $\%$ & $\mathbf{N}^{0}$ & $\%$ \\
\hline $\begin{array}{l}\text { Encontrar o pesquisador que atue na mesma área que a } \\
\text { empresa para estabelecer a parceria }\end{array}$ & 11 & 57,89 & 4 & 21,05 & 2 & 10,53 & 2 & 10,53 \\
\hline Desenvolver o projeto & 1 & 5,26 & 11 & 57,89 & 2 & 10,53 & 5 & 26,32 \\
\hline Reunir a documentação exigida & 2 & 10,53 & 8 & 42,11 & 5 & 26,32 & 4 & 21,05 \\
\hline Estabelecer a contrapartida da empresa & 3 & 15,79 & 4 & 21,05 & 7 & 36,84 & 5 & 26,32 \\
\hline Fazer o estudo de viabilidade técnica econômica e comercial & 2 & 10,53 & 4 & 21,05 & 5 & 26,32 & 8 & 42,11 \\
\hline
\end{tabular}

Fonte: Survey com empresas (2013).

Em segundo lugar foi estabelecer a contrapartida da empresa e reunir a documentação exigida. Desenvolver o projeto e encontrar o pesquisador para estabelecer a parceria não foram fatores que dificultaram a submissão para a grande maioria das firmas, indicando que os obstáculos estão mais ligados a questões burocráticas do que ao próprio objetivo do programa, que é a ideia de inovação vinculada a parceria com o meio acadêmico. Cabe destacar que a maioria das firmas, já tinham relacionamentos com o pesquisador, como será visto na próxima subseção.

\subsubsection{Relações de cooperação}

As relações de cooperação envolvem as parcerias com o pesquisador e outros agentes econômicos, bem como a utilização de infraestrutura para realização do projeto. Nesse sentido, foram avaliadas as interações realizadas antes e depois da participação no programa. Como mencionado, 14 firmas já tinham 
relacionamento com o pesquisador antes do programa, como demonstrado na Tabela 9. Dessas, 12 atribuíram média ou alta relevância a participação do pesquisador durante a realização do projeto e 2 consideraram participação de nula ou baixa importância. Das 5 que não se relacionavam antes, 2 consideraram o pesquisador importante para a realização do projeto, 2 não e 1 não respondeu.

Tabela 9: Descrição da relação de parceria entre empresa e pesquisador, segundo características referentes a participação da empresa no Pappe, Região Centro-Oeste, 2013

\begin{tabular}{|c|c|c|c|c|c|c|c|c|c|c|c|c|}
\hline \multirow{6}{*}{ 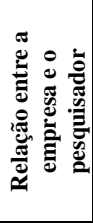 } & \multicolumn{5}{|c|}{ Grau de importância do pesquisador no projeto } & \multicolumn{3}{|c|}{ Nova cooperação } & \multicolumn{4}{|c|}{ Atingiu objetivo } \\
\hline & & $\begin{array}{c}\text { Nula ou } \\
\text { baixa }\end{array}$ & $\begin{array}{l}\text { Média ou } \\
\text { alta }\end{array}$ & Não resp. & Total & Não & Sim & Total & Não & Sim & Não resp. & Total \\
\hline & Já existia & 2 & 12 & 0 & 14 & 6 & 8 & 14 & 2 & 11 & 1 & 14 \\
\hline & Não existia & 1 & 2 & 0 & 4 & 2 & 2 & 4 & 0 & 4 & 0 & 4 \\
\hline & Não resp. & 0 & 0 & 1 & 1 & 1 & & 1 & 0 & 1 & 0 & 1 \\
\hline & Total & 3 & 14 & 1 & 19 & 9 & 10 & 19 & 2 & 16 & 1 & 19 \\
\hline
\end{tabular}

Fonte: Survey com empresas (2013).

A partir da participação no Pappe, 10 companhias geraram novas cooperações, sendo que dessas 8 já cooperavam com o pesquisador. Das 4 que não tinham relações, apenas 2 fizeram novas interações além da já estabelecida com o pesquisador, indicando que quem já coopera, tem maior chance de estabelecer novas interações. Porém, quanto aos objetivos esperados, a parceria antecipada não parece ter tido relevância, pois as 4 empresas que não tinham parcerias antes atingiram seus objetivos, enquanto 2 das que já tinham não atingiram.

Quanto a infraestrutura utilizada para o desenvolvimento dos projetos, o alto número das empresas (17) que utilizaram infraestrutura própria deve-se ao fato de que 12 empresas já tinham departamento de $\mathrm{P} \& \mathrm{D}$, sendo que dessas apenas uma utilizou a infraestrutura da universidade. Das 4 empresas que não tinham laboratório de $\mathrm{P} \& \mathrm{D}, 3$ também utilizaram infraestrutura própria e apenas 1 desenvolveu as atividades inovativas na universidade parceira. Isso mostra que a interação com a universidade está mais relacionada a utilização dos recursos humanos, nesse caso, o pesquisador, do que por conta de necessidade de usar a universidade para substituir seus laboratórios de P\&D. Por outro lado, possuir laboratórios de $\mathrm{P} \& \mathrm{D}$ não influenciou o sucesso dos projetos, pois das 4 empresas que não tinham laboratório, 3 atingiram seus objetivos com o programa.

Tabela 10: Infraestrutura de P\&D das empresas com projetos aprovados no Pappe, Região Centro-Oeste, 2013

\begin{tabular}{|c|c|c|c|c|c|c|c|}
\hline \multirow[b]{2}{*}{ Departamento de P\&D antes do Pappe } & \multicolumn{3}{|c|}{ Infraestrutura utilizada no projeto } & \multicolumn{4}{|c|}{ Atingiu objetivo } \\
\hline & Infraestrutura própria & $\begin{array}{c}\text { Infraestrutura da } \\
\text { universidade }\end{array}$ & Total & Não & Sim & Não resp. & Total \\
\hline Não & 3 & 1 & 4 & 0 & 3 & 1 & 4 \\
\hline Sim & 11 & 1 & 12 & 1 & 11 & 0 & 12 \\
\hline Não respondeu & 3 & 0 & 3 & 1 & 2 & 0 & 3 \\
\hline Total de empresas & 17 & 2 & 19 & 2 & 16 & 1 & 19 \\
\hline
\end{tabular}

Fonte: Survey com empresas (2013).

No que tange aos agentes apontados como parceiros, antes do Pappe as firmas cooperavam principalmente com concorrentes, empresas de consultoria, clientes e centros de capacitação técnica. Apesar de 14 firmas terem declarado relacionamento com pesquisadores, somente 10 afirmaram cooperação com universidades e/ou institutos de pesquisa, como pode ser visto na Tabela 11.

Embora a maioria das firmas cooperassem, a relevância das cooperações para os processos inovativos é nula ou baixa. Após a participação no programa, o maior número de empresas que considerou os agentes relevantes foi igual 5 para os casos dos concorrentes, representação e entidades sindicais. Universidades e institutos de pesquisa foram indicados como de média ou alta relevância para somente 2 e 4 empresas, respectivamente.

O programa alterou as formas de cooperação e o já pequeno número de empresas que tiveram relações de cooperação incrementadas pelo Pappe é reduzido ao descontar que a maioria já possuía tais relações antes das mesmas participarem do programa. A penúltima coluna da Tabela 11 mostra o número de empresas que atribuíram média ou alta relevância aos agentes após o Pappe e que não cooperavam antes de participar do programa. Em todos os casos, novas cooperações foram geradas. Contudo, a última coluna demonstra as empresas que realizavam cooperação antes e, após o programa, atribuíram nula ou 
baixa relevância aos agentes especificados, mostrando que a existência de cooperação não indica que as mesmas são importantes para a implementação de inovações.

Tabela 11: Atividades de cooperação realizadas pelas empresas com projetos aprovados no Pappe antes e depois da participação no Programa, Região Centro-Oeste, 2013

\begin{tabular}{|c|c|c|c|c|c|c|}
\hline \multirow{2}{*}{ Agentes das atividades cooperativas } & \multicolumn{2}{|c|}{ Frequência antes do Pappe ${ }^{\mathrm{A}}$} & \multicolumn{2}{|c|}{$\begin{array}{c}\text { Grau de relevância depois do } \\
\text { Pappe }\end{array}$} & \multicolumn{2}{|c|}{ Mudança após Pappe } \\
\hline & Acontecia & Não acontecia & Nula ou baixa & Média ou alta & Novas coop. ${ }^{\text {B }}$ & Coop.encer. $^{\mathrm{C}}$ \\
\hline Fornecedores & 9 & 9 & 7 & 3 & 2 & 1 \\
\hline Clientes & 11 & 6 & 8 & 2 & 2 & 5 \\
\hline Concorrente & 14 & 5 & 4 & 5 & 3 & 4 \\
\hline Empresas de consultoria & 12 & 6 & 6 & 3 & 2 & 6 \\
\hline Universidade & 10 & 7 & 7 & 2 & 1 & 5 \\
\hline Institutos de Pesquisa & 10 & 8 & 5 & 4 & 3 & 4 \\
\hline Centros de capac. prof. de assist. técnica e de manutenção & 11 & 7 & 5 & 4 & 2 & 3 \\
\hline Instituições de testes, ensaios e certificações & 9 & 9 & 6 & 4 & 3 & 3 \\
\hline Representação & 7 & 11 & 4 & 5 & 5 & 1 \\
\hline Entidades Sindicais & 8 & 9 & 4 & 5 & 3 & 3 \\
\hline Órgãos de apoio e promoção & 10 & 7 & 6 & 3 & 1 & 4 \\
\hline
\end{tabular}

Notas: ${ }^{\mathrm{A}}$ Acontecia rotineiramente ou raramente. ${ }^{\mathrm{B}}$ Novas cooperações: empresas que não declaram cooperação antes, mas após o Pappe atribuíram média ou alta importância. C Cooperações encerradas: declaram cooperações com estes agentes, mas atribuíram nula ou baixa relevância dos mesmos depois do Pappe.

Fonte: Survey com empresas (2013).

Em suma, pelos relacionamentos das firmas com os pesquisadores, percebe-se duas conclusões que vão ao encontro dos estudos sobre interação universidade-empresa, especificamente de que o processo interativo decorre de aprendizado: empresas que interagem parecem ter mais chances de estabelecer novas cooperações; o relacionamento antecipado com o pesquisador aumenta a importância do pesquisador para o projeto; com as parcerias, as empresas buscam conhecimento e não infraestrutura para substituir seus laboratórios de P\&D. Concomitantemente, o Pappe não aumentou as relações de cooperações das empresas, nem mesmo com as universidades e institutos de pesquisa, que é um dos objetivos do programa, resultado semelhante ao de Carrijo e Botelho (2013). Ademais, muitos relacionamentos existem, mas não foram importantes para geração de inovações.

A baixa importância das universidades e institutos de pesquisa pode estar vinculada a fragilidade dos processos interativos academia-indústria, que, em grande monta, decorrem também da fragilidade do sistema regional de CT\&I. Nesse caso, destaca-se, em particular, o tardio início das atividades de pesquisa na região, uma vez que as universidades federais e estaduais somente recentemente tem se voltado para a problemática de realizar pesquisa conjunta com o setor privado, como apontado em Almeida et. al. (2011).

\subsubsection{Atividades de inovação}

Em relação ao registro de patentes, todas as empresas que detinham patentes antes, bem como as que geraram patentes após o Pappe, declararam realizar inovações com frequência e possuir em sua estrutura laboratório de $\mathrm{P} \& \mathrm{D}$ antes de participar no programa. Anterior ao programa, 3 empresas apresentavam patentes, contudo, diferente do esperado, as patentes são de propriedade das empresas que menos gastaram com P\&D, sendo que uma delas gastou abaixo de R\$ 30 mil, conforme Tabela 12. Em termos setoriais, as patentes antes eram de firmas do setor de tecnologia (2) e industrial (1). Foram geradas patentes por somente quatro empresas, das quais uma é do setor de tecnologia e já possuía antes do programa e, das outras três que não possuíam patentes, uma também se insere no segmento de tecnologia e 2 no industrial.

Tabela 12: Empresas com projetos aprovados no Pappe, segundo características das atividades inovativas antes e depois da participação no Programa - Região Centro-Oeste

\begin{tabular}{|c|c|c|c|c|c|c|c|c|c|c|c|c|}
\hline \multirow{2}{*}{$\begin{array}{l}\text { Possuía } \\
\text { patentes } \\
\text { antes }\end{array}$} & \multicolumn{3}{|c|}{ Depto P\&D antes } & \multicolumn{6}{|c|}{ Despesas anuais com P\&D } & \multicolumn{3}{|c|}{ Gerou patente após } \\
\hline & Não & Sim & Não resp. & $\begin{array}{c}0 \text { a R\$ } \\
\text { mil }\end{array}$ & $\begin{array}{c}\mathbf{R} \$ \begin{array}{c}31 \text { a } 80 \\
\text { mil }\end{array} \\
\end{array}$ & $\begin{array}{l}\text { R\$ } 81 \text { a } \\
160 \text { mil }\end{array}$ & $\begin{array}{c}\text { R\$241 a } \\
500\end{array}$ & $\begin{array}{c}\text { R\$ } 501 \mathrm{mil} \mathrm{a} \\
\text { R\$ } 1 \mathrm{mi}\end{array}$ & Não resp. & Não & Sim & Não resp. \\
\hline Não & 4 & 9 & 3 & 7 & 0 & 2 & 2 & 2 & 3 & 13 & 3 & 0 \\
\hline
\end{tabular}




\begin{tabular}{l|c|c|c|c|c|c|c|c|c|c|c|c} 
Sim & 0 & 3 & 0 & 1 & 1 & 1 & 0 & 0 & 0 & 1 & 1 & 1 \\
\hline Total & 4 & 12 & 3 & 8 & 1 & 3 & 2 & 2 & 3 & 14 & 4 & 1 \\
\hline
\end{tabular}

Fonte: Survey com empresas (2013).

Observa-se predomínio de empresas que já tinham a inovação como uma rotina, sendo que 14 empresas realizavam busca tecnológica de forma contínua, 16 declararam algum valor com $\mathrm{P} \& \mathrm{D}$, embora a maioria (8) gastasse abaixo de R\$ 30 mil. Os principais impactos das inovações de produto e/ou processo já implementados pelas empresas antes da participação no programa estão indicados na Tabela 13. Os resultados mais relevantes referem-se à melhoria da qualidade do produto, para 16 empresas, enquanto a ampliação da gama de produtos ou serviços ofertados, criação de novas oportunidades de negócios, aumento de produtividades da empresa, capacitação de recursos humanos e introdução de inovações organizacionais foram indicados por 15 firmas.

Tabela 13: Principais impactos das inovações de produto e/ou processo já implementados antes da participação no Programa - Região Centro-Oeste

\begin{tabular}{|c|c|c|c|c|}
\hline \multirow{2}{*}{ Impactos das inovações } & \multicolumn{2}{|c|}{ Nula ou baixa } & \multicolumn{2}{|c|}{ Média ou alta } \\
\hline & No & $\%$ & No & $\%$ \\
\hline Melhorou a qualidade do produto & 2 & $10,5 \%$ & 16 & $84,2 \%$ \\
\hline Ampliou a gama de produtos ou serviços ofertados & 3 & $15,8 \%$ & 15 & $78,9 \%$ \\
\hline Permitiu manter a participação da empresa no mercado & 5 & $26,3 \%$ & 13 & $68,4 \%$ \\
\hline Promoveu maior inserção da empresa no mercado nacional & 5 & $26,3 \%$ & 13 & $68,4 \%$ \\
\hline Permitiu a empresa entra no mercado externo & 14 & $73,7 \%$ & 3 & $15,8 \%$ \\
\hline Criou novas oportunidades de negócios & 3 & $15,8 \%$ & 15 & $78,9 \%$ \\
\hline Aumentou a produtividades da empresa & 2 & $10,5 \%$ & 15 & $78,9 \%$ \\
\hline Reduziu custos de produção & 9 & $47,4 \%$ & 9 & $47,4 \%$ \\
\hline Aumentou a capacitação de recursos humanos & 3 & $15,8 \%$ & 15 & $78,9 \%$ \\
\hline Introduziu inovações organizacionais & 3 & $15,8 \%$ & 15 & $78,9 \%$ \\
\hline
\end{tabular}

Fonte: Survey com empresas (2013).

A partir do programa, as principais inovações desenvolvidas foram processo novo para o setor (12 firmas), produto novo para o mercado nacional (10), processo novo para a empresa (9) e mudanças significativas nas áreas de marketing, como apresentado na Figura 5. Mudanças no acondicionamento dos produtos e no âmbito organizacional, como alteração na estrutura organizacional e de métodos e gerenciamento para obtenção de certificação praticamente não foram realizadas.

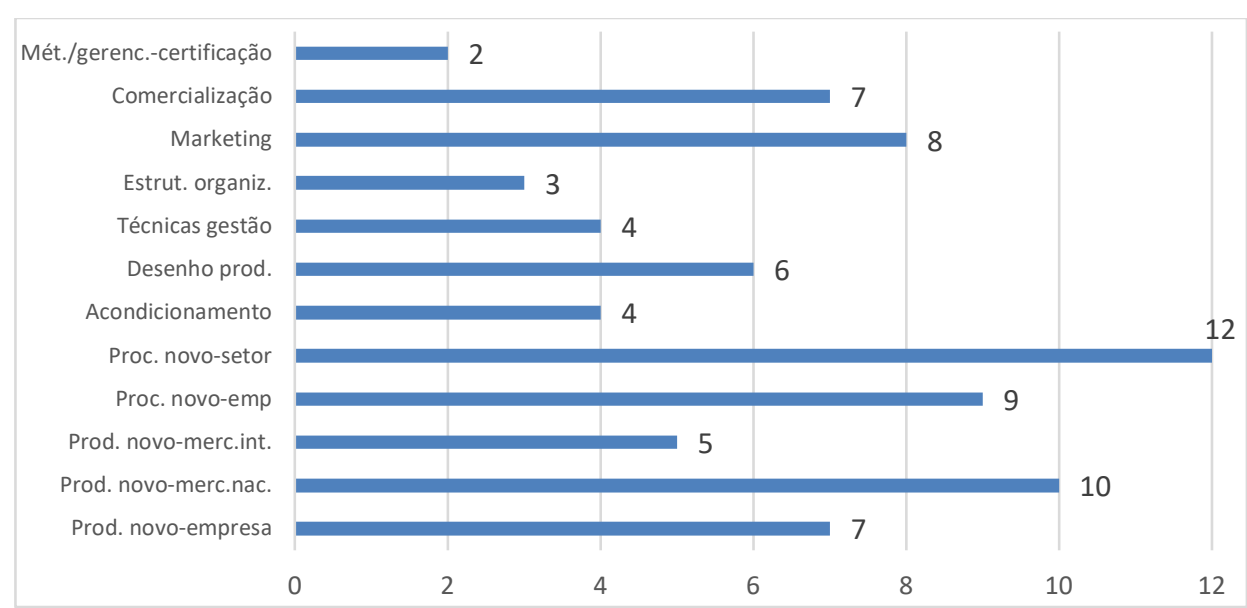

Figura 5: Tipo de inovação tecnológica desenvolvida pela empresa a partir do Pappe, 2013 Fonte: Survey com empresas (2013).

Um resultado positivo do Pappe é a inserção de algumas empresas no mercado internacional a partir de novos produtos, desenvolvidos por 5 das empresas entrevistadas. Antes do programa, apenas 3 empresas atribuíram média ou alta relevância das inovações para inserção no mercado externo (Tabela 13). 
Em relação as inovações de produto, o resultado é aquém do esperado, por duas razões principais: primeiramente, porque esta é uma das finalidades dos editais. Em segundo lugar, melhorias na qualidade e ampliação da gama de produtos estão entre os resultados mais importantes das atividades inovativas antes do programa, mostrando a importância desse objetivo para as empresas.

\subsubsection{Outros resultados e dificuldades do programa}

No que tange as expectativas das empresas beneficiadas pelos editais, tem-se que 16 atingiram seus objetivos. Tendo em vista que esse tipo de pesquisa apresenta problema de viés de seleção ${ }^{6}$, o percentual de empresas que não obtiveram sucesso pode estar subestimado, pois se espera que as empresas não satisfeitas tenham maior probabilidade de não aderir a pesquisa.

Analisados os impactos na cooperação e nas atividades inovativas, as empresas também quantificaram os impactos do programa quanto a geração de emprego, inserção em novo mercado e publicação de artigos, conforme Figura 6. Dessa forma, 12 firmas criaram novas vagas, gerando cerca de 21 novos empregos, que representa um crescimento de $10 \%$ em relação ao total de recursos humanos ${ }^{7}$. Das 19 firmas entrevistadas, 13 obtiveram inserção em novos mercados após o Pappe, sendo 6 no mercado nacional e 7 internacional. As atividades inovativas também resultaram em publicação de artigos por 6 firmas. A baixa quantidade de empresas deve-se ao fato de essa finalidade ser mais importante para as universidades do que para o meio empresarial.

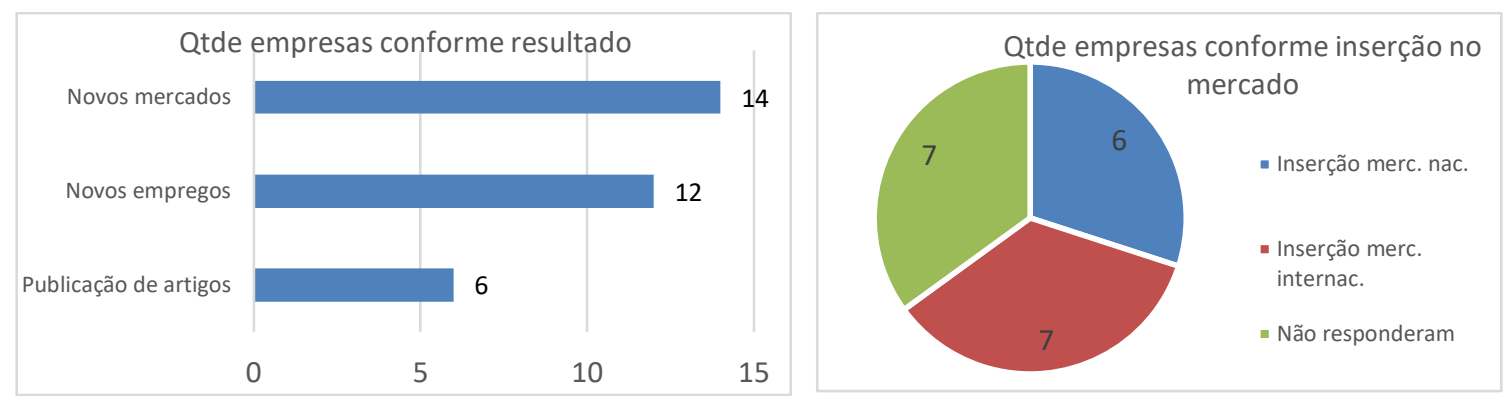

Figura 6: Outros resultados obtidos pelas empresas com projetos aprovados no Pappe após a participação no Programa, Região Centro-Oeste, 2013

Fonte: Survey com empresas (2013).

Dentre as dificuldades enfrentadas que prejudicaram o andamento do projeto, as empresas atribuíram maior relevância a falta de mão de obra qualificada e morosidade na liberação dos recursos financeiros, segundo Tabela 10. Em seguida, tem-se dificuldade para se adequar a padrões, normas e regulamentações e aos prazos curtos, reafirmando que a firmas tem problemas para se adequarem a questões burocráticas e específicas das formulações dos editais, assim como foram empecilhos diversos para submissão dos projetos.

Tabela 10: Dificuldades enfrentadas pelas empresas com projetos aprovados no Pappe que prejudicaram a implementação do projeto, Região Centro-Oeste, 2013

\begin{tabular}{|c|c|c|c|c|}
\hline \multirow{2}{*}{ Dificuldades } & \multicolumn{2}{|c|}{ Não relevante ou baixa relevância } & \multicolumn{2}{|c|}{ Média ou alta relevância } \\
\hline & $\mathbf{N}^{0}$ & $\%$ & $\mathbf{N}^{\mathbf{0}}$ & $\%$ \\
\hline Demora na liberação dos recursos financeiros & 11 & $57,89 \%$ & 8 & $42,11 \%$ \\
\hline Falta de infraestrutura adequada & 14 & $73,68 \%$ & 4 & $21,05 \%$ \\
\hline Falta de cooperação entre outras empresas & 14 & $73,68 \%$ & 4 & $21,05 \%$ \\
\hline Falta de insumos de produção & 15 & $78,95 \%$ & 3 & $15,79 \%$ \\
\hline Falta de mão-de-obra qualificada & 9 & $47,37 \%$ & 8 & $42,11 \%$ \\
\hline Dificuldade para se adequar a padrões, normas e regulamentações & 13 & $68,42 \%$ & 5 & $26,32 \%$ \\
\hline Ausência de bom relacionamento entre empresa e pesquisador & 15 & $78,95 \%$ & 3 & $15,79 \%$ \\
\hline Prazo muito curto para o desenvolvimento do projeto & 12 & $63,16 \%$ & 6 & $31,58 \%$ \\
\hline Total de empresas & \multicolumn{4}{|c|}{19} \\
\hline
\end{tabular}

Nota: Algumas empresas não responderam essa questão.

${ }^{6}$ Como as empresas podem optar ou não por participar, a amostra não é aleatória.

73 empresas geraram empregos, mas não informaram a quantidade. 
É importante destacar que falta de infraestrutura adequada e ausência de bom relacionamento entre empresa e pesquisador, que poderiam ser fatores impeditivos de execução do projeto e, por isso, questões de preocupação para os formuladores de políticas e FAPs, foram dificuldades para poucas empresas. Essa evidência é contraditória ao exposto pelas empresas no que tange a cooperação com as universidades e mostra que relacionamentos virtuosos com o pesquisador não aumentam a importância das universidades para inovação. Essa particularidade é uma pauta da pesquisa que requer maior investigação.

\section{Considerações finais}

A questão da concentração territorial das bases científicas e tecnológicas tem sido incorporada nos debates sobre desenvolvimento regional e, consequentemente, nas políticas de CT\&I federais e estaduais. Nesse aspecto, analisou-se a evolução do sistema de CT\&I da região Centro-Oeste nos anos 2000 e, em particular, os resultados do Pappe segundo a visão das empresas beneficiadas entre 2004 e 2011.

Observou-se avanços nas políticas de CT\&I, porém, as mesmas têm sido descontínuas no tempo e ainda não foram capazes de romper com o mecanismo de autorreforço que mantém a concentração regional e as disparidades dentre da região Centro-Oeste. Como a infraestrutura científica influencia os fluxos de recursos federais, a fragilidade da base científica da região reduz sua competitividade na captação de novos recursos junto às agências governamentais. O mesmo ocorre no setor produtivo, já que as firmas de setores mais avançados tecnologicamente tendem a instalar-se nos estados em que exista maiores efeitos de aglomeração.

No que tange aos resultados do Pappe, quanto a caracterização das empresas participantes, os resultados mostram que as empresas, no geral, são jovens; de pequeno porte; com atuação no território nacional e estadual; do setor de tecnologia; funcionários e sócios com nível educacional acima da média nacional; e os sócios fundadores são oriundos do próprio setor empresarial. Os resultados também apontam características importantes das parcerias universidade-empresa na região. Em primeiro lugar, que as empresas precisam de recursos de subvenção e recursos humanos (pesquisador) para implementar inovações, o que está vinculado a característica de micro e pequeno porte. Por sua vez, o programa gerou resultados positivos em termos de geração de mercados e postos de trabalho, mas quanto à mudança tecnológica, as firmas realizaram inovações, mas não foram capazes de alocar produto novo para o mercado.

Em termos de suas limitações, percebeu-se o predomínio de empresas que já tinham inovação em sua rotina. Também, o programa não aumentou as relações de cooperação das empresas, ou seja, não gerou novas parcerias, que é um dos objetivos do programa. Ademais, poucas empresas geraram novas patentes após o programa, refletindo uma tendência das firmas da região, visto que têm mantido o número de registros junto ao INPI estável, apesar do incremento dos esforços inovativos, conforme demonstrado pela PINTEC. Os fatores que tem elevado as atividades de inovação das firmas, bem como as especificidades setoriais que podem influenciar a geração de patentes abrem novas agendas de pesquisa.

Enfim, ainda que o programa apresente limitações e seja pouco inclusivo, há indícios de ser um instrumento importante de apoio à inovação na região Centro-Oeste, ao estimular a pesquisa nas empresas, impactando não apenas na geração de emprego e exploração de novos mercados, mas também nas parcerias com o setor científico, tão importantes para o amadurecimento do sistema regional de inovação. Cabe ressaltar que, o Pappe é um programa que tem passado por modificações desde sua criação e se ampara em um esforço de aprendizado institucional para se aperfeiçoar e trazer mais benefícios aos envolvidos (CARRIJO E BOTELHO, 2013).

Ademais, embora o programa não seja uma política regional, tem potencial de representar passos importantes para uma futura diminuição da concentração regional das atividades de CT\&I, mediante captação de recursos juntos ao governo federal. Sobretudo, o programa tem importância particular para a capacitação tecnológica das MPEs da região Centro-Oeste, já que a maioria das empresas deste porte apresenta certo grau de fragilidade tanto no campo gerencial, quanto tecnológico, bem como não dispõe de recursos para investimento em atividades inovativas. Nesse sentido, é importante enfatizar a 
necessidade de ampliação e aprimoramento das políticas de C,T\&I na região, definindo prioridades e traçando metas, gerando mecanismos facilitadores da interação entre os agentes do sistema de inovação que favoreçam o desenvolvimento regional.

\section{Referências}

ALBUQUERQUE, E. National systems of innovation and non-OCED countries: notes about a rudimentary and tentative "tipology”. Brazilian Journal of Political Economy, v.19, n. 4 (76), p. 35-52, 1999.

ALMEIDA, C. C. R., POVOA, L. M. C. Interação entre Universidades, Institutos e Centros de Pesquisa com Empresas na Região Centro-Oeste: experiências da EMBRAPA Cerrados. In: SUZIGAN, W.; ALBBUQUERQUE, E. M.; CARIO, S. A. F. (Orgs.) Em busca da inovação: Interações de universidades e institutos de pesquisa com empresas no Brasil.1 ed. Belo Horizonte-MG: Editora Autentica, 2011, p. 403-428.

ALMEIDA, C. C. R.; VILLELA, T. C.; CARIO, A. F.; SEABRA, F. Interação universidade-empresa na região Centro-Oeste do Brasil: características de um sistema regional de inovação imaturo. Revista de Economia, v. 37, n 4: volume especial, p.83-115, 2011.

AQUINO, M. C. A. Impacto de políticas públicas de C, T\&I no desenvolvimento: o Pappe subvenção em Pernambuco. 2013. 88f. Dissertação (Mestrado em Engenharia de Produção) - Programa de Pósgraduação em Engenharia de Produção, Universidade Federal de Pernambuco, Recife, PE, 2013.

ARAÚJO, B. C. Políticas de apoio à inovação no Brasil: uma análise de sua evolução recente. 2012. Texto de Discussão 1759. Rio de Janeiro: Ipea, 2012.

BOTELHO, A. ALMEIDA, M. Desconstruindo a política científica no Brasil: evolução da descentralização da política de apoio à pesquisa e inovação. Revista Sociedade e Estado. v. 27, n. 1, 2012. p.117-132.

CARRIJO, M. C.; BOTELHO, M. R. A. Cooperação e inovação: uma análise dos resultados do Programa de Apoio à Pesquisa em Empresas (Pappe). Revista Brasileira de Inovação, Campinas-SP, v. 12, n.2, p. 417-448, jul./dez. 2013.

CAVALCANTE, L. R. Desigualdades regionais em ciência, tecnologia e inovação (CT\&I) no Brasil: uma análise de sua evolução recente. 2011. Texto de Discussão 1574. Rio de Janeiro: Ipea, 2011.

COSTA, A. C. et al. Análise da operação de subvenção econômica à inovação no Brasil. In: Conferência Internacional LALICS 2013 "Sistemas Nacionais de Inovação e Políticas de CTI para um Desenvolvimento Inclusivo e Sustentável”, 2013. Rio de Janeiro-RJ. Anais... Rio de Janeiro: Rede LALICS, 2013.

FAPDF - Fundação de Apoio à Pesquisa do Distrito Federal. Disponível em: <http://www.fap.df.gov.br> . Vários acessos.

FAPEG - Fundação de Amparo à Pesquisa do Estado de Goiás. Disponível em: $<$ http://www.fapeg.go.gov.br/sitefapeg>. Vários acessos.

FAPEMAT - Fundação de Amparo à Pesquisa do Estado de Mato Grosso. Disponível em: $<$ http://www.fapemat.mt.gov.br>. Vários acessos.

FINEP - Financiadora de Estudos e Projetos. Ações e programas. 2016. Disponível em: <http://www.finep.gov.br/acesso-a-informacao-externo/acoes-e-programas> Acesso em: 15/06/2016.

FONSECA, M. L. M. Formulação de políticas públicas de ciência, tecnologia e inovação (CT\&I): cooperação intergovernamental em busca do desenvolvimento científico regional. In: V Congresso Consad de Gestão pública, 2012. Brasília - DF. Anais.... Brasília: Consad, 2012. 
FUNDECT - Fundação de apoio ao desenvolvimento do ensino, Ciência e Tecnologia do Estado de Mato Grosso do Sul. Disponível em:<http://fundect.ledes.net >. Vários acessos

IBGE - Instituto Brasileiro de Geografia e Estatística. Pesquisa de Inovação Tecnológica/PINTEC 2003; 2011. Dados regionais. Rio de Janeiro, 2003; 2011.

LIMA, J. G. O, et al. Impactos iniciais do programa de subvenção econômica Pappe Integração no estado de Alagoas. Anais da $25^{\circ}$ Conferência de Empreendedorismo e Ambientes de Inovação (APRONTEC). Cuiabá, 19 a 23 de outubro de 2015.

LIMA, R. J. C, et al. Análise do programa de apoio à pesquisa em empresas (Pappe) no estado de Minas Gerais. In: II Simpósio Internacional de Gestão de Projetos e II Simpósio Internacional de Inovação e Sustentabilidade, 2013. São Paulo-SP. Anais... São Paulo: UNINOVE, 2013.

LUNDVALL, B. A. National Systems of Innovation: towards a theory of innovation and interactive learning. London: Pinter Publishers, 1992.

MCTI - MINISTÉRIO DA CIÊNCIA, TECNOLOGIA E INOVAÇÃO. Dados Abertos. Indicadores. Disponível em: <http://www.mct.gov.br/index.php/content/view/740.html> Vários acessos.

MONTENEGRO, R. L. G.; DINIZ, B. P. C.; SIMÕES, R. F. Ciência e Tecnologia versus estruturas estaduais: uma análise em dados em painel (2000-2010). In: Anais do XLII Encontro Nacional de Economia. ANPEC-Associação Nacional dos Centros de Pós-graduação em Economia, 2014, Natal. Anais... Natal: ANPEC, 2014.

MORAIS, J. M. Políticas de apoio financeiro à inovação tecnológica: avaliação dos programas MCT/FINEP para empresas de pequeno porte. 2007. 2011. Texto de Discussão 1296. Rio de Janeiro: Ipea, 2007.

NELSON, R; WINTER, S. An evolutionary theory of economic change. Massachusetts: The Belknap Press of Harvard University Press, 1982.

RAPINI, M. S. O Financiamento aos investimentos em inovação no Brasil. 2010. 146 f. Tese (Doutorado em Economia) - Instituto de Economia, Universidade Federal do Rio de Janeiro, Rio de Janeiro. 2010.

RAPINI, M. S; ALBUQUERQUE, E.; CHAVES, C.; SILVA, L.; SOUZA, S.; RIGHI, H.; CRUZ, W. University-industry interactions in an immature system of innovation: evidence from Minas Gerais, Brazil. Science and Public Policy, v. 36, n.5, p. 373-386, 2009.

ROSEnBERG, N. Por dentro da Caixa-Preta: tecnologia e economia. Campinas, SP. Editora da Unicamp, 2006.

SILVA, A. S.; BOTELHO, J. B. L.; ZOGAHIB, A. L. N. Sistema de inovação em Manaus: uma avaliação da interação entre as organizações de apoio ao sistema de inovação e as empresas participantes do Programa de Apoio à Pesquisa em Empresas (Pappe). In: II Congresso Consad de Gestão Pública, 2009. Brasília-DF. Anais... Brasília: Consad, 2009.

SUZIGAN, W.; ALBUQUERQUE, E. M. A interação entre universidades e empresas em perspectiva histórica no Brasil. In: SUZIGAN, W.; ALBBUQUERQUE, E. M.; CARIO, S. A. F (Orgs.) Em busca da inovação: Interações de universidades e institutos de pesquisa com empresas no Brasil. Belo Horizonte-MG: Editora Autentica, 2011.

TORRES, P. H. Financiamento à inovação e interação entre atividades científicas e tecnológicas: uma análise a partir do Pappe. 2016. 195 f. Dissertação. (Mestrado em Economia) - Instituto de Economia, Universidade Federal de Uberlândia, Uberlândia, 2016.

VIOTTI, E. B. Fundamentos e evolução dos indicadores de CT\&I. In: VIOTTI, E. B.; MACEDO, M. de M. (Org.) Indicadores de Ciência, Tecnologia e Inovação no Brasil. Campinas: UNICAMP, 2003.

WEISZ, J. Mecanismos de apoio à inovação tecnológica. 3. ed. - Brasília: SENAI/DN, 2006. 